\title{
Defending Density
}

\author{
Michael Samuelian, FAIA, AICP
}

"There is a density level in NYC that is destructive. It has to stop and it has to stop now. NYC must develop an immediate plan to reduce density."

Governor Andrew Cuomo, March 22, 2020

\begin{abstract}
We have an aversion to density in America. Density is a continual trope in this country, blamed for all of the ills of urban life, from crime and racial unrest in the middle of the 20th century to public health concerns today. In the early stages of the COVID pandemic density was the culprit, even though we've subsequently seen outbreaks in rural areas and sprawling cities across the United States. This paper will look into the root of America's problems with density and argue that density is not the problem but the solution to the challenges of today's and tomorrow's cities. As we deplete the resources of the planet, density is our most direct pathway to recover some balance with nature. Dense living is more efficient, less carbon intensive and more environmentally sustainable. As geospatial differentiations matter less due to advances in communication technology, it's the density of people and ideas that will continue to fuel innovation. Finally, in a world that is increasingly dominated by pluralism, denser living promotes openness, tolerance and diversity.
\end{abstract}

KEYWORDS

Sustainability; Urban Planning; Climate Change; Technology; Urban Technology; Urban Development; Density; Congestion

\section{America's Distaste for Density}

Even before the devastating effects of the COVID hit the United State, dense urban environments have been challenged in American cities since the founding of the country (Jenkins, 2020). In fact, density has been decried as the source of many urban ills since the creation of the modern metropolis in the 19th century (Howard, 1902). Alternatives to dense urban environments were drawn up almost as fast as cities were being built. The very basis of zoning in the U.S. is based upon a segregation of land uses (Hirt, 2014 ) to alleviate the problems of fast-industrializing 19th century cities. This was the 
beginning of the confusion of density with overcrowding and congestion. Fast forward 100 years, and today we still confuse the two.

\section{The Benefits of Deliberate Density}

From the beginning of the COVID pandemic, density was consistently heralded as the culprit (Cuomo, 2020), blamed for the spread of the virus throughout New York City, without a mention of overcrowding. We've since learned that density isn't the problem in cities, congestion, poverty, inequity and comorbidities are (Patel, et al, 2020). We just need to look at megacities in Asia; Tokyo, Taipei and Seoul to see how thoughtfully planned dense urban environments avoided the worst of the virus (Nachman, 2021). Closer to home, we've also learned over the past year that cities and density weren't the sole or even the primary factors in transmission of COVID (Gray, 2020). The virus ultimately hit rural communities in middle America and sprawling cities such as Los Angeles worse than dense urban centers like New York, Chicago and Boston. The problem with the spread of COVID wasn't density, it was congestion, overcrowding and our failure to plan Deliberate Density.

When planned properly, deliberate density can be the solution to our urban challenges, not simply the problem. Density can mitigate overcrowding in cities by supporting the provision of infrastructure investment (Glover \& Simon, 1975) that can alleviate the negative effects of overcrowding and congestion. When thoughtfully deployed, deliberate density supports the creation of infrastructure that promotes a smart dispersal of citizens, proper sanitation, clean water, social services and state-of-the-art healthcare institutions. Density can and has been a solution to urban challenges for generations by inspiring and bolstering the creation of cultural and social institutions (Rykwert, 2002) that support people, particularly vulnerable populations.

On a more qualitative level, density is also responsible for many of the most positive aspects of many cities such as street life and culture (Rykwert, 2002). Ever since cities started attracting more and more people in the 19th century, a certain degree of crowding has created a dynamism and vibrancy that people embrace and celebrate. Density of people has translated into the vibrancy and diversity that we celebrate in today's cities. Consider Times Square on New Year's Eve, it's both dense and crowded and yet all the eyes of the world are upon it.

Density makes great cities great in other, less intense ways too. From the density of theaters in Times Square to the density of brownstones in Brooklyn, density creates value, authenticity and helps make places unique and special. The most successful and magnetic cities in the world are known for their dense urban street life and amenities 
(Rykwert, 2002). Density is why many new residents are attracted to cities that provide a density of choice and economic opportunity (Florida, 2012).

\section{Defining Density vs. Crowding}

Most of the negative attributes of density are more precisely issues of congestion, or overcrowding (Carnhan, 1974). This distinction is rarely mentioned or studied. And while density is a precondition for crowding it is not inevitable. Density is a physical condition, whereas congestion is a spatial limitation (Stokols, 1972). Density has become the bogeyman for all urban problems, from traffic and air pollution to poverty and crime, which are in reality functions of overcrowding and congestion.

When deployed deliberately and controlled for negative externalities density increases choice whereas congestion limits them. Density gives people more options as to where to live, where to shop, where to work and where to learn. Dense urban environments provide more mobility, economic opportunity and access to education (Florida, 2012).

There is also a largely invisible cultural component to congestion and a wide range of cultural sensitivities (Stokols, 1972). A crowded sidewalk in Tokyo is very different from a busy intersection in middle America. People in dense urban environments often feel and act differently in crowded conditions (Simmel, 1950) than those in less intense environments. We do not focus on the behavioral conditions associated with congestion and overcrowding. How often do we understand the contextual issues and behavioral characteristics that make us feel as though a space is crowded as opposed to buzzing and vibrant? These distinctions can be extremely subjective, especially when considered as a function of context of culture, choice and context (Stokols, 1972).

Personal choice is central to the distinction of crowding and density for many. If we look at individuals' response to density, it can be viewed through the lens of the intensity of the spatial experience, personal and cultural factors, coupled with the ability of the individual to change the situation. (Stokols, 1972). Think about the distinction between being in a busy restaurant or at a party versus sitting in traffic. In one case you likely have a choice of whether to leave or as opposed to being "stuck" in traffic.

Speaking of traffic, technology can deliver tools and strategies to mitigate the negative effects of congestion and promote densification. From Singapore to London, congestion pricing has been adopted in a number of cities around the world. The explicit goal of this strategy is to acknowledge the cost of the externalities related to automobile congestion, and incentivize alternative means of transportation. Increasingly accepted concepts such as congestion pricing are a positive indicator that we can promote density while alleviating the problems of overcrowding and congestion. (Baghestani, et al, 2020) 


\section{The Roots our American Aversion to Density}

Americans are obsessed with individuality and personal freedom, often at the cost of the collective good. If we go deeper into the differences between density and overcrowding, specifically in this country, we can see the cultural roots of our national aversion to density. The spatial limitations of crowding and congestion are a proxy for a lack of choice and the American obsession with individual rights (Jenkins, 2020). The spatial limitations that overcrowding engenders conflicts with notions of personal freedom of movement and our expansionist, manifest destiny vision of cultural dominance over the continent. Horace Greeley's infamous "go west, young man" was a reaction to the overcrowding and unhealthiness of living in Washington, DC. Simply put, in America, crowding (nee density) limits individual freedom, ergo it must be bad.

This relationship of individual freedom and personal space has been in conflict in this country since its founding. The debates between Hamilton and Jefferson framed the future of this country as either a center of commerce and trade or an agrarian economy of small family farmers spread across the vast continent in miles of checkerboard grids. But in fact, it's been 100 years since we've been a country of farmers. In 1920, the country became a majority urban population (U.S. Census, 1920) and our cities have been growing ever since. This is due to new opportunities that cities deliver to urban dwellers thanks to the benefits of density, and we should not take those benefits for granted.

As the world shifted from an agricultural economy to an urban and mercantile-based one there were seismic shifts in the relationship of individuals to the collective and the state changed dramatically (Mumford, 1961). What was previously a cohesive community bound by feudal laws was increasingly disaggregated and more dominated by capital and industry. People were drawn to cities as economic opportunities fueled by technology, and together they powered the expansion and industrialization of the 19th century.

Industrialization also caused physical challenges to growing urban environments, specifically with regard to land use within cities. The need and desire to segregate increasingly noxious industrial uses from residential areas led to the invention and widespread adoption of municipal zoning, starting in Germany in the 1870's (Hirt, 2014). Zoning was quickly adopted in the United States by the 1920's just as the country was urbanizing. Cities began regulating not only land use, but density as well. Suddenly, governments had broad tools to regulate the density of their cities and suburbs. 
In dense environments, social life grew increasingly challenging in the 20th century, crime rose and urban poverty and density was blamed (Rothstein, 2017). Post-World War II, urban renewal efforts looked to de-densify the centers of American cities and promote the development of suburbs, building on a late 19th century English theory of metropolitan development (Howard, 1902). The reality of much urban renewal and dedensification of city centers was to stem "white flight" and resulted in the targeted displacement of large communities of Blacks from dense inner-city neighborhoods. (Rothstein, 2017)

By the 1960's, the post-war attacks on traditional urban life provoked an outcry and a new appreciation for the complex street life of dense urban neighborhoods (Jacobs, 1961). The complexity of inner-city neighborhoods was embraced and celebrated. The historic preservation movement focused on the benefits of preserving largely low-rise, high density neighborhoods (Wood, 2008). We began to appreciate the urban design and social benefits of density. The renewed focus on the complex social life of cities embraced a less scientific and more organic approach to the study of cities (Alexander, 1965).

The 1960's and 1970's also saw the dawn of a new age of computing. Many futurists noted the impending impacts of technology on cities. While simultaneously place was being celebrated and the centers of American cities were being revitalized, a cohort of futurists saw a different future, shaped by technology (Toffler, 1970). One in which location mattered less than communications and interactions. There was an increasing disassociation between value creation and geography due to telecommunications. Remote work was becoming increasingly possible and telecommuting was born.

At the dawn of the consumer technology revolution in the mid-1990's, this acceleration had moved from the office to the home. To some, technology was seen as an agent to renew the Jeffersonian ideal of a more pastoral United States. (Mitchell, 1995). The internet in particular was both absorbing content and connecting people like never before possible. Emails, video chats, online communities were beginning to displace the value of face-to-face communication. Cities were being unrooted and beginning to be shaped by bandwidth (Mitchell, 1995).

But paradoxically, over the next 25 years technology had a countervailing effect, increasing the importance and power of large, often global cities. This aggregation was seen as a self-perpetuating pattern of network expansion (Batty, 2013). And in 2012, the globe saw a tipping point of urban life where more than half the global population lived in cities. 
As technology took a more central role in the development, study and governance of cities (Townsend, 2013) a renewed debate emerged on the relationship of density and technology. While much of the smart city movement focused on the optimization of urban systems through urban sensing and data collection (Townsend, 2013). There was a quick counter reaction to new issues of data privacy and security. Urban power dynamics shifted to technology companies and local governments were being "disrupted" by new technological innovations. This was predicted in the 1990's when Bill Mitchell stated that "in smart cities, control of code is power" (Mitchell, 1995). Unfortunately, today, that power is increasingly in fewer and fewer corporate hands.

The consolidation of power in the technology industry cannot and should not be replicated with new urban technologies in our cities. Even before the 2020 pandemic, cities were changing fast and unregulated technologies were disrupting location-based industries such as real estate, hospitality and transportation. We cannot let that be the model for future cities, particularly with regard to addressing the global challenges of climate change.

\section{Climate Change and Density - WHY CITIES ARE A SOLUTION?}

Notwithstanding the changes that technology is bringing to cities, we still live in a physical world. We are sensitive to cold and warm, rain and droughts. We need shelter. And increasingly more and more of us are living in coastal areas. Historically, cities were often located near coastlines or rivers to promote and enhance trade. Today $40 \%$ percent of the global population lives near coastlines (UN, N.D.) and waterways, making them even more vulnerable to climate change, rising seas levels and extreme weather events.

Climate change is not only already underway, it is dramatically affecting both existing cities and global migration patterns (Kalin, 2021). Neither of these will abate any time soon. Cities across the country already affected by the changing climate vary from older established cities such as New Orleans to New York to newer and growing ones like Miami and Houston. Cities large and small are scrambling to adapt their infrastructure to the new realities of rising seas and extreme weather (Dawson, 2017).

Globally, this intersection of urbanization and climate change is setting us on a course for disaster. Over the next 30 years, we will add 2.5 billion people to cities around the world (" $68 \%$ of the world's population", 2018). By 2050,2 out of 3 people on the planet will live in cities, dramatically increasing the amount of urban area built today around the world. The question will be, what kind of cities will they be? Will future cities be more like Phoenix or New York? 
We will need multiple solutions to mitigate the effects of climate change, from reducing greenhouse gas emissions and migrating from a carbon economy, to living with less and recycling more. We will need environmentally sustainable urban strategies to help both absorb growth and maintain some balance with natural systems. One of the mechanisms that we have at our disposal is density. We can deploy what has been called "humanity's greatest invention" (Glaser, 2011), cities, and their respective dense urban environments.

While denser cities alone will not solve the climate crises, they can certainly help by absorbing population growth across the country and around the world. Density allows more efficient use of resources through the use of mass transit and the general tendency for smaller dwelling units, which use less energy per resident (Dodman, 2009).

Denser cities can help us reduce our impact on the environment, particularly with regard to carbon and greenhouse gas (GHG) emissions (Kurvinen \& Saari, 2019). In many cities from Europe to North and South America, per capita GHG emissions are substantially lower in dense urban environments, particularly in wealthier countries. Studies show that urban residents have roughly $70 \%$ less the impact on the environment as their national peers on average (Dodman, 2013).

We must accept the fact that more people on the planet will continue to stress our ecosystem. Dense environments are designed to allow residents to use fewer resources and have a smaller impact on the planet. It's both easier and more efficient to densify a city vertically, than continue to sprawl (Batty, 2018).

Today we are using more resources that the planet can provide (Chakrabarti, 2013). In the future, as our population continues to grow, they can be accommodated in dense urban environments with low per capita carbon footprints or continue the sprawl that is overtaking the arable land that feeds us and wetlands that protect us from rising seas and storm events.

Further, migration patterns due to climate change are putting ever increasing pressure on dense urban environments along coastal areas in developing countries (Dodman, 2009). As more vulnerable populations flee land made unlivable by a heating planet, they are moving to more vulnerable areas. With more frequent climate events and storms, these vulnerable populations with more vulnerable areas we will see the intersection of climate and urbanization with even more potentially devastating effects. 
Density helps to amortize the high cost of public infrastructure (Kurvinen \& Saari, 2019). Given the environmental damage of climate change already underway, greater density supports the provision of infrastructure that can help mitigate the effects of rising seas and extreme weather on citizens and particularly vulnerable populations. Further, dense environments also help provide social institutions and government services that aid in recovery after extreme weather and climate events (Dodman, 2009).

We've seen examples of how dense environments address climate induced public health disasters. Some of the biggest successes in fighting the spread of the COVID occurred in well-managed and regulated dense cities such as Singapore, Hong Kong, Seoul and Taipei (Nachman, 2021). These examples prove that density isn't the main factor in public health challenges. And yet today, we are confronted with a new paradigm wherein U.S. cities are on the defensive. We must again defend the benefits of density as one of the clearest ways that we can promote a more tolerant, innovative and environmentally sustainable world.

\section{Mitigating the Centrifugal Forces on Density by Technology}

Cities used to be located and largely defined by their geography and proximity to natural resources (Mumford, 1961), but technology is fast changing that. As predicted in the 1960 's, a transition is taking place that is changing the concept of the city as a physical and geospatial entity (Batty, 2018). And as the physical location of cities becomes less important and less dependent on natural resources for commerce such as rivers or deep harbors, the digital interactions that occur within them become more important. These interactions are powered by its citizens who are far more mobile than ever before.

As we've seen particularly during the COVID pandemic that emptied out cities around the world, cities are not just the physical containers that we observe. They are largely defined by the interactions of people. Many cities have become empty containers, lacking the vibrancy that the density of people and activities created. Is an empty Times Square still relevant without throngs of tourists and dozens of nightly Broadway performances? And while many New Yorkers do not miss traffic or the congestion of sidewalks, many miss the dynamism and vibrancy of urban life (Seinfeld, 2020) and aren't giving up on urban living.

While technology has given us opportunities to spread apart, it has also given us a new understanding of the benefits of density and social engagement. We are beginning to appreciate the value proposition of density in terms of interactions that occur more organically within cities. Density provides the opportunities for new and unplanned 
interactions to happen. Cities are essentially giant search engines (Glaeser, 2011) for finding nearly anything you want, a job, a mate, or a great meal.

Over the last 200 years, cities have centered themselves largely as places for economic activity (Mumford, 1961). Both symbolically and physically the workplace has been central to our concept of the modern city, whether it was a factory in the 19th century or an office building in the 20th. Technology and COVID have combined and mutated into a world of displaced value creation, challenging our concept of the city. Many workers and companies and workers are embracing this change as the future of work. But telecommunications and virtual meetings have limitations for creative brainstorming and mentorship of new employees. Online learning leaves many behind. And let's not even discuss what an online first date must be like.

\section{A virtual life has limitations.}

As we transform from a society based on energy to one based on information (Batty, 2018), we will have choices in where we locate like never before. Some will choose remote work, remote learning and rural living. But others will continue to choose density, embracing the dynamics, diversity and activation of urban centers over dispersed ones.

As systems evolve, they embrace complexity. And while technology is drawing us apart today, cities have been incredibly good at adapting to changes over time. From the industrial revolution to the advent of the automobile, and from fires, floods and terrorist attacks, cities have been resilient (Campanella \& Vale, 2005).

Over the past 30 years as the internet has taken over, destroyed and disrupted scores of industries, cities have survived and thrived like never before. Intuitively telecommunications should be spreading us further and further apart, but it hasn't. Ed Glaeser noted this "paradox of the modern metropolis" (Glaeser, 2011) wherein proximity or nearness is becoming more important as the cost of time and connecting across distances is becoming less so. Technology is connecting people physically as much as it is connecting them virtually, in fact it's making the physical and social connections all the more important.

The complexity of social systems and cities have been embraced by an incredible range of urbanists, from the beginning of the post-war preservation movement in the 1960's (Jacobs, 1965) to the tech-enabled globalization of the early 21st century (Glaeser, 2011). At the same time, our definition of cities is also expanding geographically across traditional physical limits. 
With the acceleration of working from home, learning from home and online shopping, we need to redefine what density means to us. We need to continually challenge the concept of what makes a city attractive. Density does not define cities - but it is an important indicator of one. Cities embrace complexity, and its citizens do too.

Cities evolve more organically than rationally (Batty, 2013), they adapt and change based upon the actions of millions of individuals engaged in billions of interactions. And it's the intensity of these interactions, as much as the density that makes cities places that people are attracted to. And with new urban technologies, we can now get a picture of urban dynamics like never before. The question is, will technologies help us build smarter, denser cities, or continue to be used to spread us further apart?

Traditionally, density, distance and contiguity represented the key forces defining cities as geographic objects (Batty, 2018). For generations, cities were modeled as radial diagrams of values related to real estate decreasing from the center, but today, cities are structured in far more complex ways, there are multiple dependencies and structures which have multivariate dependencies and relationships (Alexander, 1965).

As we transition from a world of cities defined by physical density to one based upon intensity of interactions, we can begin to understand the network properties of those cities. As urban systems develop, we can identify the importance and hierarchy of nodes, where interactions occur. As nodes lose their specific geospatial definition, our focus shifts to the value creation of the interactions that are occurring, the underlying social and economic network powering those interactions

For example, does it matter today, or in the future, if you are working in a cafe, your living room or a Midtown Manhattan office building? The activity matters predominantly, not the location. But cities provide more opportunities for those nodes, a greater density of options for where and how that activity can occur. The more nodes in a fixed space the greater the density of potential interactions and flexibility of their occurrence (Batty, 2018), thus supporting more social networks and complex social systems.

Before the pandemic, cities were flourishing due to advances in technology, but today it's aiding in the potential recurrence of de-densifying American of city centers (Rothstein, 2017). Technologies are allowing people to connect, work, learn and live as never before. This is a challenging traditional notion of the benefits of density and cities.

Technology has historically helped cities grow and prosper as centers of culture, invention and innovation. While real estate values have often had a centripetal force on cities, technology has often had the opposite effect, spreading cities out further and 
further. From the 19th century onward, advances in transportation and manufacturing technologies have drawn residents and workers further from the center of cities. Sometimes this was a conscious planning effort to provide better conditions for working people (Howard, 1898) but often it was also racially and socially motivated to further segregate races and classes of workers (Rothstein, 2017).

And while the benefits of technology have been asymmetrically delivered to those who can afford them, (Zukin, 2020) tech can also be a platform for more equitable redistribution of resources, greater connectivity and stronger communities. But we have a choice to control the technology or allow it to control us. Communication technologies in particular are well positioned for enhanced collaboration across geospatial, social, economic and class division (Mitchell, 1995). In 2020, technologies - particularly cell phone video footage and police body cameras - have also shined a bright light on social issues such as police brutality, poverty and racial inequity.

The existing diversity and density of cities can be intelligently deployed to better connect the silos in cities (Townsend, 2013), but more importantly can increase the connection of citizens to their local governments. To date, many new technologies have been generated by top-down processes and overlaid onto existing cities. But by empowering citizens with new technologies, we can expand opportunities. We should be using the tools of urban technology to no longer simply focus on the density of people in cities, but on the density and intensity of activities, and never before have we had as much information on our urban environments as today.

The granular level of urban data now available, from cars and bicycles, to energy use and consumer spending (Ratti, et al, 2006) are giving us a new perspective of urban systems and understanding of the metabolism of the city like never before. Data collection can also be deployed for less useful, or even nefarious purposes. Information is best when it's bidirectional (Townsend, 2013). We need to not just measure our cities through sensors, we need data to build a resilient bottom-up approach to living in the cities of the future. If we are going to power future cities with data, we must ensure that we are empowering citizens with that same data equitably.

Urban data analytics is changing our view of cities, adding a level of dynamics never before understood in real time (Batty, 2013). We are able to discover patterns of use to improve urban management and processes while improving our knowledge and performance of cities.

Data can also be power. While cities have always been centers of power, that power was rarely equitably distributed. Today, code is power (Mitchell, 1995) and fewer and 
fewer corporate entities have that code. But we can redistribute it through open-source data to empower citizens and promote the openness, diversity and social mobility that have been the attraction to urban living for centuries (Mumford, 1961).

\section{Density and Innovation}

Jane Jacobs was among the first to highlight the role of diversity of both firms and people in powering innovation and city growth (Jacobs, 1961), and since then economists have recognized that diversity is important to economic performance.

As cities expand and densify, they become more open, tolerant and diverse (Florida, 2012). In an increasingly pluralized society, we will need this to survive and thrive. It's clear that dense urban living changes people's attitudes and makes them more open. Being confronted daily by differences in culture, religion, race or beliefs often builds empathy.

Since the invention of the metropolis in the 19th century, mankind has been adapting to the over stimulation (Simmel, 1950) that density delivers. This open attitude has propelled humanity to new heights of cultural and artistic expression, institutional development, new personal freedoms and innovations (Rose, 2005). Simply put, cities invite intellect and ambition. The urban citizen is not only more open to new ideas, but more also innovative (Florida, 2012) both out of want and need.

Denser cities also provide more complex and sophisticated support networks for industry and entrepreneurs that promotes competition and a greater specialization of labor. This specialization provokes people to embrace multiple points of views and perspectives (Florida, 2012) and an openness that influences people's ability to acquire new skills quickly. Simply put, density drives innovation.

This becomes a self-supporting system, wherein cities promote innovation and simultaneously attract more innovative people. For the last twenty years, Richard Florida has explored this phenomenon in great detail in his seminal writings on the Creative Class. Cities today are powered by people that are attracted to professions that are primarily concerned with exploring, developing and communicating new ideas (Florida, 2012).

\section{Destiny's Embrace of Diversity, Openness and Tolerance}

People with high levels of the open to experience characteristic are more mobile and much more likely to cluster in specific geographic areas (Florida, 2008) where there's a 
greater density, but more importantly a great density and diversity of experiences and amenities.

Denser cities also promote a heightened degree of tolerance than rural, suburban or otherwise less dense environments (Florida, 2012). Tolerance and an openness to diversity provides an additional source of economic advantage since new ideas are generated most efficiently in places where different lifestyles and perspectives are tolerated.

Increasing mobility, and the decoupling of geospatial land value with economic values means that cities are increasingly competing for talent. Talent isn't fixed to a place, but it can be attracted to one. Dense urban environments also tend to have lower barriers to entry, embracing immigration. In fact, there are more high-skilled immigrants in the US than low-skill. (Florida, 2012).

The value proposition of cites is no longer about where is a city, but who is the city? (Florida, 2008). People, not geography are the new determinants of value in cities. People are the critical resource of the new age. This has far reaching effects on our economic and social geography and the nature of our communities. We just need to learn how to accommodate growing cities with density, not without it.

This increasing mobile workforce, place - not geography - has become the central organizing principle of our time. Cities must attract talent to remain competitive, resulting in a growing geographic segregation of the creative class and other classes (Florida, 2018). This creative class specifically shares values and is characterized by individuality, self-expression and openness. The places that this new mobile workforce are attracted to are also characterized by diversity, openness and tolerance, all hallmarks of dense urban environments.

\section{Can Virtual Connectivity Replace the Value of Proximity (and Density?)}

Or Why can't I work in my pajamas forever?

A significant amount of press in 2020 focused on companies making announcements that their work from home policy will be extended, some indefinitely. Many of these companies also happen to be technology companies. Somewhat contradictory, these same companies are gobbling up office space in cities. The good news is that it seems as though capital is taking a long view on density, irrespective of their press releases on their work from home policies. 
Some medium-sized dense urban centers, such as Miami and Austin are experiencing a mini-boom (Bowles, 2021). Although they look different, these cities share a number of traits. They are tolerant and diverse with vibrant cultural scenes and an urban density that provides residents and workers with a range of urban amenities. Neither are rural or particularly sprawling. Even in 2020, the mobile creative class is selecting density over the alternatives. No one goes to Miami to work in their pajamas.

Much of the focus over the past year of lockdowns has been on the connective power of technology for (some kinds of) work. Many have focused on the productivity gains of working from home, particularly on the corporate level. For those privileged enough to be able to work from home, this has been a boom, eradicating long commutes, office gossip and the need to put on work clothes. But with all the focus on the productivity "gains" that the virtual workplace seems to produce, there is much being lost that we don't always see. Young workers are losing out on training, mentorship and the "real life" experience that will shape their future careers. A generation of workers are not being exposed to the social cues that occur in meetings and negotiations, much less undertaking the creative idea generation that occurs in brainstorming sessions and impromptu meetings.

Research shows that oftentimes invention occurs on the individual level, but implementation occurs in groups (Cain, 2012). How sustainable is a workforce and a team dynamic and company loyalty when everyone's main coworker is their computer screen? Companies may be short sighted in their embrace of the remote work phenomena. They are trading short term gains in the reduction of office rents with longterm losses in terms of employee satisfaction and ultimately potentially their loyalty to the enterprise. This trend was predicted at the beginning of the era of cheap computing power in the 1990's in which a renewed utopian vision of a "return to cottage industry" (Topher, 1970) was predicted. In the early 2000's the reality was quite different until today, so we again find ourselves defending density in America.

On a social level we cannot and should not ignore the question of who's else being left behind in the virtual city? While young titans of industry may be able to recover a lost year of experience, we probably can't say the same for children that are losing time in the classroom. We are only now beginning to appreciate the social and psychological costs of remote learning. It will be years before we know the impacts on an entire generation of young people, most of whom come from vulnerable populations.

According to Oxford Languages, sustainability is defined as "the ability to be maintained at a certain rate or level or the avoidance of the depletion of natural resources in order 
to maintain an ecological balance". Can this remote lifestyle be maintained? We are increasingly hearing reports of "covid fatigue", and while this has been most prominently identified as a partisan issue around individual freedoms, it's an important indicator of our human need for social connections, not simply virtual ones. We must find a balance between the overwhelming benefits to the planet and society that density delivers and our national aversion to density.

\section{CONCLUSION - If we don't actively Defend Density, who will?}

The dissociation of community and geography predates cities. In ancient times, before there were cities, there were civitas which bound people together through shared beliefs. It wasn't until early nomadic tribes settled down that they created urbs, or the place-based community (Mitchell, 1995). We are living in a world that is again a decoupling place and community, but we can actually do both. We can build communities that are both virtually connected and physically dense and diverse. Deliberate density can mitigate the negative effects of congestion and climate change while building more empathetic, diverse and resilient communities.

Virtual connections are not enough to create community. There is a crucial role for the urban. While today's cities may not be based on the specialness of a particular place, it is based on the specialness and uniqueness of human interactions. As cities shift from their grounding in geography, to their identity in cyberspace, it's their citizens and residents who matter most.

At current urbanization rates, over the next 30 years, we will add 2 billion people to cities around the world (Roser, et al, 2019). These new urban citizens can live in dense cities or sprawling suburbs. If it's the former and we embrace dense urban environments that provide social institutions and physical infrastructure to support smart density, then we can live in greater balance with the resources of the planet and promote a more equitable and empathetic society. If it's the latter, carbon will continue to dominate the atmosphere, technology will continue to tear us apart and we will continue to live in segregated echo chambers of division.

The only way that we can sustainably accommodate growth is through increasing density in places that can support it. This is the best way to mitigate the damage of sprawling 20th century cities. And as technology makes geography less relevant to value creation, we must rely on the only resource that technology can't replace, our humanity. As we evolve quickly into a more pluralistic society, dense cities will continue to embrace diversity and tolerance. A more open, empathetic and collaborative world is 
the only way that we can collectively address the devastation that climate change will bear upon us.

We need to confront our national fears of density. We need more proponents of dense urban environments to confront the atomization of society that technology is continuing to promote. While dense cities bring people together unregulated technology creates echo chambers that only propagates class segregation and racial division. If we don't defend density today, our future is far more precarious than our present.

While technology has powered the building (and dispersal) of great cities, their resilient power has come from their irreplaceable asset, their citizens. Technology will not supply the answer to our uncertain future, people will. 
Sources Cited

$68 \%$ of the world population projected to live in urban areas by 2050 , says UN ( 16 May 2018). Retrieved from https://www.un.org/development/desa/en/news/population/2018-revision-of-worldurbanization-prospects. htm/\#: : text=News68\%25\%20of\%20the\%20world\%20population $\% 20$ projected\%20to\%20live\%20in, are as\%20by\%202050\%2C\%20says\%20UN\&text=Today \%2C\%2055\%25\%20of\%20the \%20world's, increase\%20to\%2068\%25\%20by\%202050.\&text=The\%20urban\%20pop ulation\%20of\%20the,to\%204.2\%20billion\%20in\%202018

Alexander, C., A city is not a tree. Sustasis, 1966.

Bowles, Nellie (2021). "They Can't Leave the Bay Area Fast Enough", The New York Times, 14 January.

Baghestani, M.T., Allahviran, M., \& Gao, O., Center for Transportation, Environment and Community Health, Evaluating the Traffic and Emissions Impacts of New York City Cordon Pricing Center for Transportation, Environment, and Community Health, May, 2020

Batty, Michael, The New Science of Cities. The MIT Press, 2013.

Batty, Michael, Inventing future cities, MIT press, 2018

Cain, Susan, Quiet: The Power of Introverts in a World that Can't Stop Talking, Crown, 2013.

Carnhan, D., Gove, W., Galle, Omer R., Urbanization, Population Density, and Overcrowding: Trends in the Quality of Life in Urban America, Social Forces, Vol. 53:1, Sept 1974

Chakrabarti, Vishaan P., A Country of Cities, Metropolis Press, 2013

Dawson, Ashley, Extreme Cities: The Peril and Promise of Urban Life in the Age of Climate Change, Verso, 2017. 
David D (April 2, 2009), Urban Density and Climate Change, Analytical Review of the Interaction between Urban Growth Trends and Environmental Changes. United Nations Population Fund.

Florida, Richard, The Rise of the Creative Class Revisited, Basic Books, New York, 2012.

Florida, Richard, Who's Your City?: How the Creative Economy is Making Where to Live the Most Important Decision of Your Life, Basic, 2008

Florida, Richard, The New Urban Crisis: How Our Cities Are Increasing Inequality, Deepening Segregation, and Failing the Middle Class-and What We Can Do About It, Hachette Books, 2018.

Glaeser, Edward, Triumph of the City: How Our Greatest Invention Makes Us Richer, Smarter, Greener, Healthier, and Happier. Penguin, 2011.

Gray, Nolan, (September 17 2020) Problem: Overcrowding Solution: Density, City Journal. Retrieved fromhttps://www.city-journal.org/overcrowding-is-a-factor-in-covidinfection

Hirt, Sonia A., Zoned in the USA The Origins and Implications of American Land Use Regulation, Cornell University Press, 2014.

Howard, Ebenezer, Garden Cities of To-Morrow, Faber and Faber, London, 1902.

Jacobs, Jane, "The Death and Life of Great American Cities", Random House, 1961.

Jenkins, Clay, (April 1, 2020) Thomas Jefferson, Epidemics and His Vision for American Cities, Governing Magazine. Retrieved from

https://www.governing.com/context/Thomas-Jefferson-Epidemics-and-His-Vision-forAmerican-Cities.html

Kurvinen, A. \& Saari, A., Sustainability, Urban Housing and Infrastructure Costs, January 2020

Mumford, Lewis, The City in History, Harcourt, Brace, Jovanovich, 1961.

Nachman, Lev, (February, 1, 2021) Taiwan's COVID-19 Triumph, how did Taiwan manage to make the best of 2020's worst situation? Retrieved from https://thediplomat.com/2021/01/taiwans-covid-19-triumph/ 
Patel, J.A., Nielsen, F.B.H, Badiani, A.A., Public Health, Poverty, inequality and COVID19: the forgotten vulnerable, Volume 183, June 2020, Pages 110-111, May 2, 2020

Ratti, C., Frenchman, D., Pulselli \& Riccardo M., Environment and Planning B: Planning and Design, Mobile Landscapes: Using Location Data from Cell Phones for Urban Analysis, Volume: 33 issue: 5, October 1, 2006.

Rose, Jonathan, The Well-Tempered City: What Modern Science, Ancient Civilizations and Human Nature Can Teach Us About the Future of Urban Life, 2015.

Roser, M, Hannah Ritchie, H, \& and Esteban Ortiz-Ospina, E, (May 2019), World Population Growth, Our World in Date, As Retrieved

https://ourworldindata.org/world-population-growth

Rothstein, Richard, The Color of Law: A Forgotten History of How Our Government Segregated America, 2017.

Rykwert, Joseph, The Seduction of Place: The History and Future of Cities, Vintage, 2002

Seinfeld, Jerry, (2020). "So You Think New York Is Dead? It's Not", The New York Times, 24 August

Simmel, Georg, The Metropolis and Mental Life. Translated by Kurt Wolf, Free Press, 1950.

Toffler, Alvin, Future Shock, Bantam, 1970

Townsend, Anthony, Smart Cities: Big Data, Civic Hackers, and the Quest for a New Utopia, W.W. Norton Company, 2014.

Stokols, D., Psychological Review, On the Distinction Between Density and Crowding, Vol.79. No. 2, 1972.

UN Atlas of the Oceans, (N.D.) Retrieved from

http://www.oceansatlas.org/subtopic/en/c/114/ 
U.S. Census Bureau, History: Urban and Rural Areas, (N.D.) Retrieved from https://www.census.gov/history/www/programs/geography/urban_and_rural_areas.html ?cssp=SERP\#: :text=The $\% 201920 \% 20$ census $\% 20$ marked $\% 20$ the,population $\% 20$ was \%20defined\%20as\%20urban.

Vale, Lawrence J., Campanella, Thomas J., The Resilient City: How Modern Cities Recover from Disaster, Oxford, 2005.

Wood, Anthony, Preserving New York: Winning the Right to Preserve New York City's Landmarks, Routledge, 2008

Zukin, Sharon, The Innovation Complex, Oxford, 2020. 